\title{
Critical Role of Dorsomedial Hypothalamic Nucleus in a Wide Range of Behavioral Circadian Rhythms
}

\author{
Thomas C. Chou, ${ }^{1,2}$ Thomas E. Scammell, ${ }^{2}$ Joshua J. Gooley, ${ }^{1,2}$ Stephanie E. Gaus, ${ }^{1,2}$ Clifford B. Saper, ${ }^{2}$ and Jun Lu ${ }^{2}$ \\ ${ }^{1}$ Department of Neurobiology and Program in Neuroscience, Harvard Medical School, Boston, Massachusetts 02115, and ${ }^{2}$ Department of Neurology, \\ Harvard Medical School and Beth Israel Deaconess Medical Center, Boston, Massachusetts 02215
}

\begin{abstract}
The suprachiasmatic nucleus (SCN) contains the brain's circadian pacemaker, but mechanisms by which it controls circadian rhythms of sleep and related behaviors are poorly understood. Previous anatomic evidence has implicated the dorsomedial hypothalamic nucleus (DMH) in circadian control of sleep, but this hypothesis remains untested. We now show that excitotoxic lesions of the DMH reduce circadian rhythms of wakefulness, feeding, locomotor activity, and serum corticosteroid levels by $78-89 \%$ while also reducing their overall daily levels. We also show that the DMH receives both direct and indirect SCN inputs and sends a mainly GABAergic projection to the sleep-promoting ventrolateral preoptic nucleus, and a mainly glutamate-thyrotropin-releasing hormone projection to the wakepromoting lateral hypothalamic area, including orexin (hypocretin) neurons. Through these pathways, the DMH may influence a wide range of behavioral circadian rhythms.
\end{abstract}

Key words: suprachiasmatic nucleus; sleep; feeding; corticosteroid; locomotor activity; melatonin

\section{Introduction}

In many animals, the suprachiasmatic nucleus (SCN) strongly influences circadian rhythms of sleep-wake behaviors, but the pathways mediating these influences are poorly understood. SCN efferents project only lightly to major hypothalamic sleep-wake regulatory cell groups such as the lateral hypothalamic orexin (also called hypocretin) neurons and ventrolateral preoptic nucleus (VLPO) (Abrahamson et al., 2001; Chou et al., 2002). Instead, most SCN efferents target the subparaventricular zone (SPZ), which resides just dorsal to the SCN, whereas less intense projections reach other, mainly medial hypothalamic targets (Watts et al., 1987; Kalsbeek et al., 1993; Morin et al., 1994). Cell-specific lesions of the dorsal SPZ markedly reduce circadian rhythms of body temperature $(\mathrm{Tb})$ but not of sleep and locomotor activity (LMA), whereas lesions of the ventral SPZ markedly reduce circadian rhythms of sleep and LMA with smaller effects on Tb rhythms (Lu et al., 2001). Hence, the SPZ may play a major role in these circadian rhythms, but SPZ efferents essentially parallel and augment those of the SCN, again targeting medial hypothalamic areas (Watts et al., 1987; Morin et al., 1994) with poorly understood roles in regulating sleep and associated behaviors.

One target of SCN and SPZ efferents, the dorsomedial hypothalamic nucleus (DMH), is implicated in autonomic stress re-

\footnotetext{
Received May 5, 2003; revised Sept. 25, 2003; accepted Sept. 26, 2003.

This work was supported by National Institutes of Health Grants NS33987, HL60292, and MH01507. We thank Quan Ha and Minh Ha for excellent technical assistance. We also appreciate Drs. John Assad, Charles Czeisler, Fred Davis, Joel Elmquist, Robert Greene, and Robert McCarley for their helpful discussions and feedback.

Correspondence should be addressed to Dr. Clifford B. Saper, Department of Neurology, Beth Israel Deaconess Medical Center, 330 Brookline Avenue, Boston, MA 02215. E-mail: csaper@caregroup.harvard.edu. Copyright $\odot 2003$ Society for Neuroscience 0270-6474/03/2310691-12\$15.00/0
}

sponses, in feeding, and in the circadian release of corticosteroids (for review, see Bellinger et al., 1976; Kalsbeek et al., 1996; Bernardis and Bellinger, 1998; DiMicco et al., 2002), although many of these studies used electrolytic lesions or drug injections that have limited anatomic specificity. The DMH has also been hypothesized to modulate the circadian rhythm of sleep via projections to the locus coeruleus (LC) (Aston-Jones et al., 2001; Gonzales et al., 2002); however, the role of the DMH in the circadian regulation of sleep has not been tested.

We and others have recently shown a strong $\mathrm{DMH}$ projection to the VLPO (Chou et al., 2002; Deurveilher et al., 2002), a region in which lesions cause long-lasting insomnia (Lu et al., 2000). VLPO neurons are most active during sleep (Sherin et al., 1996; Szymusiak et al., 1998) and promote sleep via GABAergic projections to wake-promoting regions such as the histaminergic tuberomammillary nucleus and other monoaminergic nuclei (Sherin et al., 1998; Steininger et al., 2001; Lu et al., 2002). The DMH also projects intensely to the lateral hypothalamic area (LHA) (Thompson et al., 1996), where many neurons contain the wakepromoting neuropeptide orexin (Sakurai et al., 1998). Loss of orexin signaling produces symptoms of the sleep disorder narcolepsy (Chemelli et al., 1999; Lin et al., 1999; Hara et al., 2001), but it is unknown whether DMH efferents target orexin neurons.

We hypothesize that the DMH critically influences circadian rhythms of sleep via direct projections to sleep-wake regulatory sites. To test this hypothesis, we examined the effects of cellspecific DMH lesions on circadian rhythms of sleep-wake behavior and associated functions such as LMA, feeding, Tb, corticosteroid secretion, and melatonin secretion. We next examined $\mathrm{DMH}$ projections and neurotransmitters involved in $\mathrm{DMH}$ projections to the VLPO and LHA that might influence circadian sleep cycles. 


\section{Materials and Methods}

Animals and housing. Animal protocols were approved by Harvard University and Beth Israel Deaconess Medical Center Animal Care and Use committees. We used 68 male Sprague Dawley rats (275-300 gm; Harlan Sprague Dawley, Indianapolis, IN) for lesion experiments and 18 for anatomic tracing experiments. Rats were housed at $22-25^{\circ} \mathrm{C}$ with ad libitum food and water and ventilation fans to mask ambient noise. Lesioned and shamlesioned rats were entrained to a 100 lux light/ dark cycle (lights on 7 A.M.-7 P.M.) for 1 week after surgeries and then placed into constantly dark chambers for the second week of the experiment.

Anatomic tracer injections and lesions. Under deep chloral hydrate anesthesia and aseptic conditions, 12-24 $\mathrm{nl}$ of the excitotoxin ibotenic acid (100 $\mu \mathrm{g} / \mu \mathrm{l}$ saline; Sigma, St. Louis, MO), or 3-15 $\mathrm{nl}$ of the anterograde tracer biotinylated dextran (BD) $(125 \mu \mathrm{g} / \mu$ l saline; Molecular Probes, Eugene, OR), or the retrograde tracers cholera toxin B subunit (CTB) $(10 \mu \mathrm{g} / \mu$ l saline; List Biological, Campbell, CA) or fluorogold (5 $\mu \mathrm{g} / \mu \mathrm{l}$ in saline; Fluorochrome, Denver, CO) were injected into the brain using glass micropipettes and a compressed air delivery system described previously (Amaral and Price, 1983; Chou et al., 2002). Glass pipettes had small tip diameters $(\sim 20 \mu \mathrm{m})$ and did not cause visible tissue damage outside of a very narrow track. Sham-lesioned control rats were injected with $15 \mathrm{nl}$ of saline instead of ibotenic acid. DMH injections were placed $3.5 \mathrm{~mm}$ posterior to bregma, $8.5 \mathrm{~mm}$ ventral to the dura, and $0.5 \mathrm{~mm}$ lateral to the midline. Coordinates for other brain regions were adapted from a standard atlas (Paxinos and Watson, 1997).

Sleep, $\mathrm{Tb}$, and locomotor activity recordings. We placed four screw electrodes (Plastics One, Roanoke, VA) into the skull to record the electroencephalogram (EEG) and two electrodes into the nuchal muscles to record the electromyogram (EMG) as described previously ( $\mathrm{Lu}$ et al., 2001). The EEG electrodes were placed $2 \mathrm{~mm}$ to the left and right of the midline and $2 \mathrm{~mm}$ rostral and $3 \mathrm{~mm}$ caudal to bregma. Electrodes were inserted into sockets and fixed with dental cement to the skull. This socket was connected to a cable that fed EEG-EMG signals to a commutator (Plastics One), allowing free rotation of the animal. Acclimation to cables and recording chambers began 2-3 d after surgery. EEG-EMG signals were amplified by Grass amplifiers (AstroMed Inc., West Warwick, RI); EEG signals were filtered to exclude frequencies $<0.5$ or $>35$ $\mathrm{Hz}$, whereas EMG signals were filtered to exclude frequencies $<10$ or $>35 \mathrm{~Hz}$. One hundred twenty-eight samples per second of EEG-EMG data were acquired by a personal computer equipped with an analog-todigital acquisition card (National Instruments) controlled by ICELUS (G-systems; M. Opp, University of Michigan) and LabVIEW software (National Instruments). EMG signals were integrated into $1 \mathrm{sec}$ bins to reduce disk storage requirements. EEG-EMG data were scored in $12 \mathrm{sec}$ bins using previously described criteria for wake, non-rapid eye movement (NREM), or rapid eye movement (REM) sleep (Lu et al., 2000). Briefly, NREM sleep was identified by a preponderance of highamplitude, low-frequency $(<4 \mathrm{~Hz})$ EEG activity, whereas wakefulness was characterized by a preponderance of low-amplitude, fast EEG activity and highly variable muscle tone. REM sleep was identified by very low EMG activity and a low-amplitude EEG, frequently with a predominance of spectral power within the theta range $(4-7 \mathrm{~Hz})$. Scoring was done before histological examination; hence the scorer was unaware of the extent of the lesions.

Intravenous lines and serum hormone measurements. SILASTIC tubing for blood withdrawal was filled with heparinized saline and inserted $4 \mathrm{~cm}$
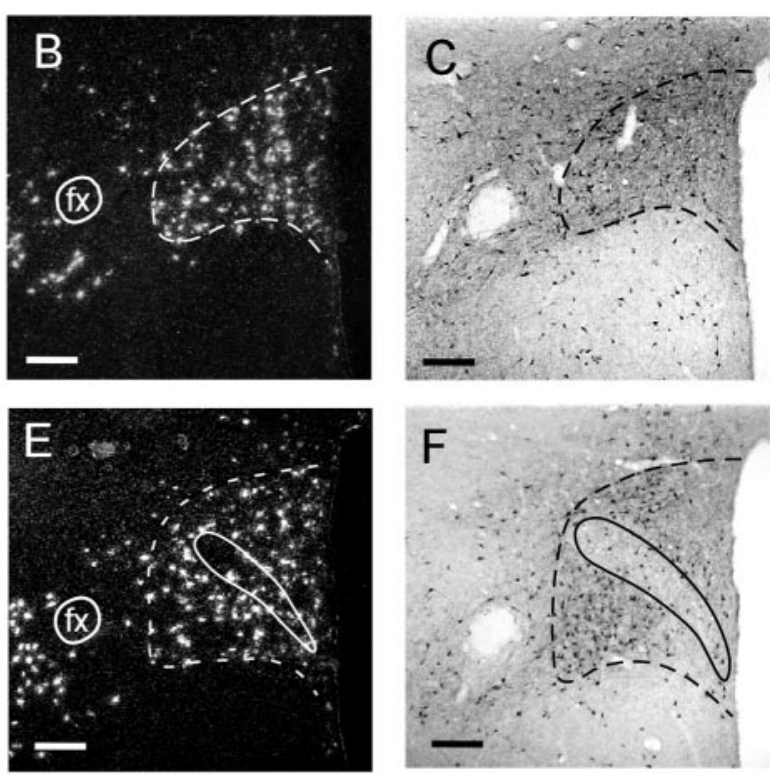
$\begin{array}{ll}\text { TRH mRNA } & \begin{array}{l}\text { CTB-labeled neurons } \\ \text { after VLPO injection }\end{array}\end{array}$

Figure 1. Anatomic markers of DMH borders (dashed lines) in Nissl-stained coronal sections $(A)$ and after in situ hybridization for TRH mRNA ( $B$ ). Retrograde tracer injections into the VLPO also label many DMH neurons ( $C$. D-F show these same markers at a caudal DMH level where the pars compacta (solid outline) is apparent. Scale bars, $200 \mu \mathrm{m}$.

into the femoral vein as described previously (Elmquist and Saper, 1996). The tubing was sutured in place, and its free end was glued to a polyethylene catheter that was passed under the skin, exteriorized between the scapulas, and plugged with a wire stylet. Catheters were flushed every 2-3 $\mathrm{d}$ with heparinized saline to ensure patency. Seven to eight days after surgery, these rats were placed in constant dim light ( $<10$ lux). Fourteen days after surgery, $0.5 \mathrm{ml}$ blood samples drawn at 4 A.M., 10 A.M., 4 P.M., and 10 P.M. were centrifuged for $5 \mathrm{~min}$ at $5000 \mathrm{rpm}$, and the supernatant was frozen at $-20^{\circ} \mathrm{C}$ and radioimmunoassayed for melatonin, corticosterone, and cortisol (Diagnostech International, Osceola, WI). Rats were placed in a towel during blood withdrawal to minimize handling stress and were habituated to this handling procedure once a day for $3 \mathrm{~d}$ before blood withdrawal. Approximately $30 \mathrm{sec}$ of handling was typically required to obtain each serum sample.

Tissue preparation. Rats were perfused with $0.9 \%$ saline followed by $10 \%$ neutral buffered formalin (Sigma). Brains were removed, equilibrated overnight in $20 \%$ sucrose in PBS with $0.01 \%$ sodium azide, and then cut on a freezing microtome into 30 or $40 \mu \mathrm{m}$ sections.

Counts of SCN, SPZ, DMH, and LHA cells. To delineate nuclear boundaries, sections mounted on glass slides were Nissl counterstained in $0.25 \%$ thionin in $0.2 \mathrm{~m}$ acetate buffer, $\mathrm{pH} 4.5$, for $1 \mathrm{~min}$, placed in $1 \%$ acetic acid for 1-5 min to differentiate stained structures, dehydrated in graded alcohols, cleared in xylenes, and coverslipped.

To quantify the extent of DMH area lesions, we counted Nissl-stained neurons within counting boxes that encompassed the $\mathrm{DMH}$ as defined by various anatomic markers (Fig. 1). These definitions of the $\mathrm{DMH}$ closely agree with cytoarchitectural borders (Thompson et al., 1996) and essentially exclude major LHA cell groups such as orexin and melanin concentrating hormone $(\mathrm{MCH})$ neurons, which we found constituted only 2 and $4 \%$ of DMH neurons, respectively. Nissl-stained DMH neurons were counted in six coronal $40 \mu \mathrm{m}$ sections spaced $160 \mu \mathrm{m}$ apart; the pars compacta of the DMH (an elongated diagonal region densely packed with small neurons) (Fig. 1) appeared mainly in the two most caudal sections. This compact part of the DMH (Paxinos and Watson, 1997 ) is also referred to as the "posterior part" of the DMH (Swanson, 1998).

Neurons with identifiable nuclei were counted in DMH counting 
boxes placed upright just above the $\mathrm{VMH}$, abutting the third ventricle. Box widths and heights were determined from the expression pattern of thyrotropin-releasing hormone (TRH) mRNA and were, in rostral to caudal order, as follows: $0.67 \times 0.3,0.67 \times 0.4,0.67 \times 0.4,0.67 \times 0.5$, $0.67 \times 0.8$, and $0.5 \times 0.8 \mathrm{~mm}$. Because most pars compacta neurons lack $\mathrm{TRH}$, do not project to the VLPO, and appear cytoarchitecturally distinct from the surrounding DMH, they were not included in counts of DMH neurons. In each region in which cell counts were obtained, average diameters of nuclei were not different between lesioned and control animals ( $p>0.1$ ), making it unnecessary to perform corrections to determine relative cell loss.

Neurons in the LHA were counted in a rectangular box placed just lateral to the $\mathrm{DMH}$, extending $400 \mu \mathrm{m}$ lateral to the fornix and having the same height as the DMH counting box at that level. Retrogradely labeled neurons with recognizable nuclei in the SCN and SPZ were counted within boundaries described previously (Lu et al., 2001); briefly, the SCN was identified by its small, densely packed Nissl-stained profiles, whereas ventral SPZ neurons were counted within a vertical $300 \times 100 \mu \mathrm{m}$ box just dorsal to the SCN, and dorsal SPZ neurons were counted within a $300 \times 200 \mu \mathrm{m}$ box parallel to and just below the ventral border of the paraventricular hypothalamic nucleus (PVH).

Period, phase, and amplitude analysis. To quantify circadian rhythms, we used two methods: a circadian index (CI) calculation and a cosinor analysis. The cosinor amplitudes of sleep, LMA, and $\mathrm{Tb}$ were calculated from the following formula:

$$
\begin{aligned}
& C=\frac{1}{N} \sum_{\mathrm{n}=0}^{\mathrm{N}-1} x_{\mathrm{n}} \cos \left(\frac{2 \pi \mathrm{n}}{\mathrm{N}}\right) \\
& S=\frac{1}{N} \sum_{\mathrm{n}=0}^{\mathrm{N}-1} x_{\mathrm{n}} \sin \left(\frac{2 \pi \mathrm{n}}{\mathrm{N}}\right) \\
& \text { Amplitude }=\sqrt{C^{2}+S^{2}}
\end{aligned}
$$

where $x_{\mathrm{n}}$ is data from the $n$th hour after sleep recordings began, and $N$ is the number of hours of data. For sleep and Tb data calculations we used $2 \mathrm{~d}$ of data $(N=48$; days $14-16$ after surgery), whereas for LMA calculations we used $6 \mathrm{~d}$ of data $(N=144$; days $10-16$ after surgery). In a few animals (four DMH lesioned; two sham-operated controls) sleep recordings started 4-5 d, instead of $7 \mathrm{~d}$, after the onset of constant darkness. The cosinor amplitudes and circadian indices of rhythms in these rats were not statistically different from the rest of their respective groups ( $p>0.1$; all comparisons), and hence these rats were grouped with the remaining lesioned and control rats.

The cosinor method assumes a nearly $24 \mathrm{hr}$ period, which was confirmed by determining the circadian period of each rat. Circadian periods were assessed by curve-fitting 7-8 $\mathrm{d}$ of $\mathrm{Tb}$ data in constant darkness to the following sinusoidal wave: $y=k+A \sin [2 \pi(x-\phi) / \tau]$, where $x$ and $y$ are the independent and dependent variables, $k$ is the offset, $A$ is the amplitude of the sinusoid, $\phi$ is the circadian phase, and $\tau$ is the circadian period. Curve-fitting was performed using Origin (Microcal Software) using starting parameters $A=1, k=37, \phi=0, \tau=24$, and iterating until the $\chi^{2}$ goodness of fit converged to a minimum value (typically $<0.1$ ). The average circadian period was $24.16 \pm 0.20 \mathrm{hr}$ (mean $\pm \mathrm{SD}$ ) in shamlesioned rats and $24.14 \pm 0.20 \mathrm{hr}$ in $\mathrm{DMH}$-lesioned (DMHx) rats. These periods exceeded $24 \mathrm{hr}$ by only $\sim 0.6 \%$.

The circadian indices of sleep, LMA, and Tb were calculated from the following formula: C.I. $=\left(\right.$ mean $_{\text {night }}-$ mean $\left._{\text {day }}\right) /$ mean $_{24 \mathrm{hr}}$, normalized to $100 \%$ for control group, where mean $_{\text {day }}$ is the average over the subjective day, mean $_{\text {night }}$ is the average over the subjective night, and mean $24 \mathrm{hr}$ is the average over the entire day. Onsets of subjective day and night were calculated for each rat using the following formula: subjective day onset $=7: 00$ A.M. $+n *($ period $-24 \mathrm{hr})$, where $n$ is the number of days after onset of constant darkness.

Statistics. Comparisons between DMHx and unlesioned rats were made using a two-tailed unequal variance Student's $t$ test, and correlations between DMH neurons and circadian amplitudes were made using linear regressions. A one-way ANOVA followed by Fisher's post hoc test was used to test variations in cortisol levels with respect to circadian time (CT).

Food intake. Food pellets in wire-top cage lids were weighed at 7 A.M. and 7 P.M. 2-3 d before sleep recordings began in a subset of the rats used for sleep recordings. Successive measurements were subtracted to determine daytime and nighttime food consumption. Because circadian phase information was not available until after the experiment, food measurement times could not be corrected for circadian phase drifts; however, subsequent calculations showed only minor phase drifts averaging $0.6 \%$ per day.

Immunohistochemistry. Immunohistochemistry was performed on floating sections as described previously (Chou et al., 2002). Primary antibodies were goat anti-CTB (1:30,000; List Biological), rabbit antiTRH (1:10,000; generous gift from R. Handa, Colorado State University), rabbit anti-fluorogold (1:25,000; Chemicon), rabbit anti-glutamate (1:1000; generous gift from Dr. P. Petrusz, University of North Carolina), and rabbit anti-orexin-A (1:10,000; Phoenix Peptides). Rats used for TRH immunohistochemistry received colchicine injections into the lateral ventricle (18 mg in $12 \mu \mathrm{l}$ saline) $36 \mathrm{hr}$ before they were killed to enhance immunoreactivity in cell bodies. In experiments in which immunostaining was followed by in situ hybridization, all immunohistochemical reagents were made with water treated with diethylpyrocarbonate (Sigma). Omission of primary antibodies resulted in no immunoreactivity above background. Adsorption controls have been reported previously for the antibodies that we used against orexin-A (Chen et al., 1999), TRH (Suzuki et al., 2001), and glutamate (Hepler et al., 1988). Specificity of immunostaining for CTB and fluorogold was indicated by the lack of detectable immunostaining in uninjected rats.

Riboprobes and in situ hybridization. Plasmid vector containing $3.2 \mathrm{~kb}$ of the glutamic acid decarboxylase 67 (GAD67) gene (generous gift from N. Tillakaratne, University of California, Los Angeles) (Erlander et al., 1991), 1241 bp of the preproTRH gene (GenBank M36317) (generous gift from Tony Hollenberg, Beth Israel Deaconess Medical Center), or 970 bp of the type-2 vesicular glutamate transporter (VGLUT2) gene (generous gift from P. Guyenet, University of Virginia) were linearized with SalI, HindIII, or XhoI and transcribed with T3, SP6, or T7 polymerase, respectively, to produce antisense mRNA probes. ${ }^{35} \mathrm{~S}$-radiolabeled probes were transcribed, hybridized, and detected using photographic emulsion as described previously (Marcus et al., 2001).

Quantification of double labeling. Fluorescence immunohistochemistry for CTB or fluorogold was combined with radiolabeled in situ hybridization for several neurochemical markers. Hybridizing cells were identified as those expressing three times background level of silver grains in the overlying photographic emulsion, and double-labeled neurons were identified by comparing dark-field views (showing silver grains) with epifluorescence illuminated views of the same tissue section. Freefloating immunohistochemistry labeled neurons in two distinct layers on both surfaces of the tissue, whereas photographic emulsion preferentially detected cells at the top surface of the tissue, and cells at the bottom layer were much less likely to have overlying silver grains. Hence, we computed double-label percentages only for CTB-immunoreactive neurons closer to the top surface of the tissue than the bottom.

\section{Results}

DMH area lesions markedly reduce circadian rhythms of sleep-wake behavior and LMA

Thirty-two rats received bilateral ibotenic acid injections into the DMH. Fourteen of these cases were excluded from analysis because lesions were asymmetric ( $>3: 2$ ratio of $\mathrm{DMH}$ cells lost between two sides) or because lesions involved the dorsal SPZ, which is critically required for expression of the $\mathrm{Tb}$ circadian rhythm (Lu et al., 2001). Of the remaining 18 rats, 10 rats had lesions ablating $>80 \%$ of DMH neurons (the DMHx group). These DMHx rats averaged $510 \pm 150$ (average \pm SEM) DMH neurons in a $1: 4$ series of sections, a $92 \pm 2 \%$ reduction from control rats, which averaged $6170 \pm 260 \mathrm{DMH}$ neurons.

We measured amplitudes of sleep, LMA, and Tb rhythms us- 
Table 1. Subjective day, night, and 24 hr total values of wakefulness, NREM, REM, LMA, and Tb for sham-operated rats or rats with DMH, VMH, DHA/PH, or LHA lesions

\begin{tabular}{|c|c|c|c|c|c|c|}
\hline & & Shams $(n=6)$ & $\operatorname{DMH}(n=10)$ & $\operatorname{VMH}(n=5)$ & $\mathrm{DHA} / \mathrm{PH}(n=4)$ & LHA $(n=5)$ \\
\hline \multirow{5}{*}{ Wake } & Daily total (hr) & $11.9 \pm 0.4$ & $11.0 \pm 0.2^{*}$ & $11.7 \pm 0.7$ & $11.7 \pm 0.8$ & $10.8 \pm 0.3^{*}$ \\
\hline & Subjective day & $4.3 \pm 0.3$ & $5.2 \pm 0.1^{*}$ & $3.6 \pm 0.2$ & $4.3 \pm 0.4$ & $3.8 \pm 0.6$ \\
\hline & Subjective night & $7.6 \pm 0.3$ & $5.8 \pm 0.1^{*}$ & $8.1 \pm 0.5$ & $7.4 \pm 0.3$ & $7.0 \pm 0.5$ \\
\hline & Circadian index & $100 \pm 15 \%$ & $20 \pm 7 \% *$ & $137 \pm 8 \%$ & $97 \pm 18 \%$ & $98 \pm 32 \%$ \\
\hline & Cosinor & $100 \pm 11 \%$ & $34 \pm 5 \% *$ & $133 \pm 12 \%$ & $113 \pm 9 \%$ & $99 \pm 9 \%$ \\
\hline \multirow[t]{5}{*}{ NREM } & Daily total (hr) & $9.9 \pm 0.4$ & $10.5 \pm 0.2$ & $10.1 \pm 0.6$ & $9.9 \pm 0.6$ & $10.8 \pm 0.2$ \\
\hline & Subjective day & $6.1 \pm 0.2$ & $5.5 \pm 0.1^{*}$ & $6.7 \pm 0.2$ & $6.0 \pm 0.3$ & $6.7 \pm 0.5$ \\
\hline & Subjective night & $3.8 \pm 0.3$ & $5.0 \pm 0.1^{*}$ & $3.5 \pm 0.5$ & $3.9 \pm 0.5$ & $4.1 \pm 0.4$ \\
\hline & Circadian index & $100 \pm 14 \%$ & $21 \pm 6 \% *$ & $138 \pm 22 \%$ & $89 \pm 9 \%$ & $101 \pm 33 \%$ \\
\hline & Cosinor & $100 \pm 9 \%$ & $42 \pm 5 \% *$ & $123 \pm 13 \%$ & $107 \pm 9 \%$ & $110 \pm 10 \%$ \\
\hline \multirow[t]{5}{*}{ REM } & Daily total (hr) & $2.2 \pm 0.1$ & $2.5 \pm 0.1^{*}$ & $2.1 \pm 0.2$ & $2.4 \pm 0.2$ & $2.3 \pm 0.1$ \\
\hline & Subjective day & $1.6 \pm 0.1$ & $1.3 \pm 0.34^{*}$ & $1.7 \pm 0.1$ & $1.8 \pm 0.2$ & $1.5 \pm 0.1$ \\
\hline & Subjective night & $0.6 \pm 0.0$ & $1.2 \pm 0.01^{*}$ & $0.4 \pm 0.1^{*}$ & $0.7 \pm 0.1$ & $0.9 \pm 0.1$ \\
\hline & Circadian index & $100 \pm 13 \%$ & $12 \pm 7 \%^{*}$ & $140 \pm 11 \% *$ & $127 \pm 11 \%$ & $58 \pm 27 \%$ \\
\hline & Cosinor & $100 \pm 13 \%$ & $27 \pm 3 \%^{*}$ & $134 \pm 9 \%$ & $119 \pm 7 \%$ & $75 \pm 21 \%$ \\
\hline \multirow[t]{5}{*}{ LMA } & Daily counts per hour & $73.0 \pm 10.4$ & $23.9 \pm 2.7^{*}$ & $55.8 \pm 9.0$ & $40.3 \pm 10.7$ & $40.5 \pm 3.5^{*}$ \\
\hline & Subjective day & $57.0 \pm 10.4$ & $23.5 \pm 2.9^{*}$ & $40.1 \pm 7.4$ & $32.9 \pm 8.6$ & $32.0 \pm 2.9^{*}$ \\
\hline & Subjective night & $88.9 \pm 10.9$ & $24.5 \pm 3.2^{*}$ & $71.6 \pm 11.3$ & $47.8 \pm 12.9$ & $49.0 \pm 6.2^{*}$ \\
\hline & Circadian index & $100 \pm 19 \%$ & $9 \pm 2 \%^{*}$ & $126 \pm 22 \%$ & $88 \pm 8 \%$ & $87 \pm 26 \%$ \\
\hline & Cosinor & $100 \pm 15 \%$ & $21 \pm 4 \% *$ & $90 \pm 24 \%$ & $86 \pm 20 \%$ & $101 \pm 23 \%$ \\
\hline \multirow[t]{5}{*}{$\mathrm{Tb}$} & Daily average $\left({ }^{\circ} \mathrm{C}\right)$ & $37.4 \pm 0.1$ & $37.1 \pm 0.1^{*}$ & $37.4 \pm 0.1$ & $37.4 \pm 0.2$ & $37.2 \pm 0.1$ \\
\hline & Subjective day & $37.1 \pm 0.1$ & $37.0 \pm 0.1$ & $37.1 \pm 0.1$ & $37.1 \pm 0.2$ & $36.9 \pm 0.2$ \\
\hline & Subjective night & $37.7 \pm 0.1$ & $37.3 \pm 0.1^{*}$ & $37.6 \pm 0.1$ & $37.7 \pm 0.1$ & $37.6 \pm 0.1$ \\
\hline & Circadian index & $100 \pm 10 \%$ & $67 \pm 7 \%$ & $100 \pm 7 \%$ & $103 \pm 14 \%$ & $115 \pm 19 \%$ \\
\hline & Cosinor & $100 \pm 8 \%$ & $75 \pm 5 \% *$ & $102 \pm 5 \%$ & $109 \pm 12 \%$ & $143 \pm 29 \%$ \\
\hline
\end{tabular}

Circadian indices and cosinor amplitudes are also given as a percentage of saline-injected sham controls. Asterisks indicate significant difference from sham-operated rats $(p<0.05)$.

ing the CI, which reflects relative values of these parameters during the subjective day versus subjective night, independently of overall homeostatic changes (Lu et al., 2001). The CI requires an accurate determination of subjective day and night onsets, which drift gradually in constant darkness because free-running circadian periods are not exactly $24 \mathrm{hr}$. The required phase corrections were minor, however, because the periods of $\mathrm{Tb}$ waveforms were found to be close to $24 \mathrm{hr}$ in all rats, averaging $24.14 \mathrm{hr}$ for DMHx rats and $24.16 \mathrm{hr}$ for sham-operated controls, with a SD of $0.2 \mathrm{hr}$ in each group. To further rule out the possibility of bias attributable to circadian phase errors, we also determined circadian amplitudes using a cosinor analysis, which makes no assumptions about circadian phase. The cosinor, however, has the drawback of underestimating nonsinusoidal contributions to waveforms, which can be substantial in normal sleep-wake rhythms.

DMHx rats had marked reductions in circadian rhythms of REM sleep ( $88 \pm 7 \%$ CI reduction; $73 \pm 3 \%$ cosinor reduction), NREM sleep (79 $\pm 6 \%$ CI reduction; $58 \pm 5 \%$ cosinor reduction), and LMA ( $91 \pm 2 \%$ CI reduction; $79 \pm 4 \%$ cosinor reduction) $(p<0.001$ each), whereas $\mathrm{Tb}$ rhythms showed much smaller reductions in amplitude $(33 \pm 7 \%$ CI reduction; $25 \pm 5 \%$ cosinor reduction; $p<0.05)$. Rats with partial $(<80 \%)$ lesions of the DMH $(n=8)$ had proportionately smaller reductions in sleep and LMA circadian rhythms, and across all 24 lesioned or shamoperated rats, the number of surviving DMH neurons correlated strongly with circadian indices of NREM sleep $(r=0.74 ; p<$ $0.001)$, REM sleep $(r=0.85 ; p<0.001)$, and LMA $(r=0.70 ; p<$ 0.005 ) (see Fig. $3 A-C$ ), and correlated more weakly with the CI of $\mathrm{Tb}(r=0.49 ; p<0.05)$ (see Fig. $3 E)$. The numbers of surviving $\mathrm{DMH}$ neurons also correlated strongly with cosinor amplitudes of NREM sleep $(r=0.80 ; p<0.001)$, REM sleep $(r=0.90 ; p<$ $0.001)$, and LMA $(r=0.70 ; p<0.001)$ and correlated more weakly with cosinor amplitudes of $\mathrm{Tb}(r=0.44 ; p<0.05)$.

Hourly sleep, LMA, and Tb data plotted with respect to CT further confirmed that DMHx rats had markedly flattened circa- dian rhythms of sleep, wakefulness, and LMA, compared with sham-operated control rats (see Fig. $4 A-D$ ). Sham-operated rats showed marked increases in wakefulness at the beginning of the subjective night (CT12) that were sustained for much of the night (see Fig. 4A), whereas DMHx rats showed a much smaller increase at CT1 2 that lasted only $\sim 2 \mathrm{hr}$ (see Fig. $4 A, B$ ). Conversely, at the beginning of the subjective day (CT0), control rats showed a prolonged increase in NREM sleep, whereas DMHx rats showed smaller increase in NREM sleep and no increase in REM sleep. Unlike sleep and LMA rhythms, the Tb circadian rhythm did not appear markedly attenuated by DMH lesions (see Fig. $4 E$ ). Individual DMHx rats exhibited prominent 3-4 hr ultradian cycles of sleep and wakefulness (see Fig. $4 F, G$ ), similar to those seen after lesions of the SCN or ventral SPZ (Mistlberger et al., 1987; Edgar et al., 1993; Lu et al., 2001). Hence, DMH area lesions may disrupt some of the same physiological processes as SCN or SPZ lesions.

\section{$\mathrm{DMH}$ area lesions reduce total wakefulness, LMA, and Tb}

DMHx rats had marked reductions in total daily wake time, LMA, and average daily Tb (Table 1), suggesting an overall physiologically activating influence of the $\mathrm{DMH}$. The reduction in LMA was particularly marked, with DMHx rats averaging $580 \pm$ 70 LMA counts per $24 \mathrm{hr}$ day, a threefold reduction from the sham average of $1750 \pm 250$ counts per day $(p<0.001)$. DMH lesions significantly reduced total daily wakefulness by $0.9 \mathrm{hr}$, from $11.9 \pm 0.4$ to $11.0 \pm 0.2 \mathrm{hr} / \mathrm{d}(p<0.05)$, because of increases in both NREM and REM sleep (Table 1). DMH lesions also reduced average daily $\mathrm{Tb}$ levels from $37.4 \pm 0.1$ to $37.1 \pm$ $0.1^{\circ} \mathrm{C}(p<0.02)$.

\section{Lesions adjacent to the DMH}

The LHA is heavily implicated in regulating wakefulness and sleep, raising the possibility that effects seen in DMHx rats could be attributed to LHA cell loss, particularly in the perifornical area (PeF) of the LHA just lateral to the DMH; however, DMHx rats 


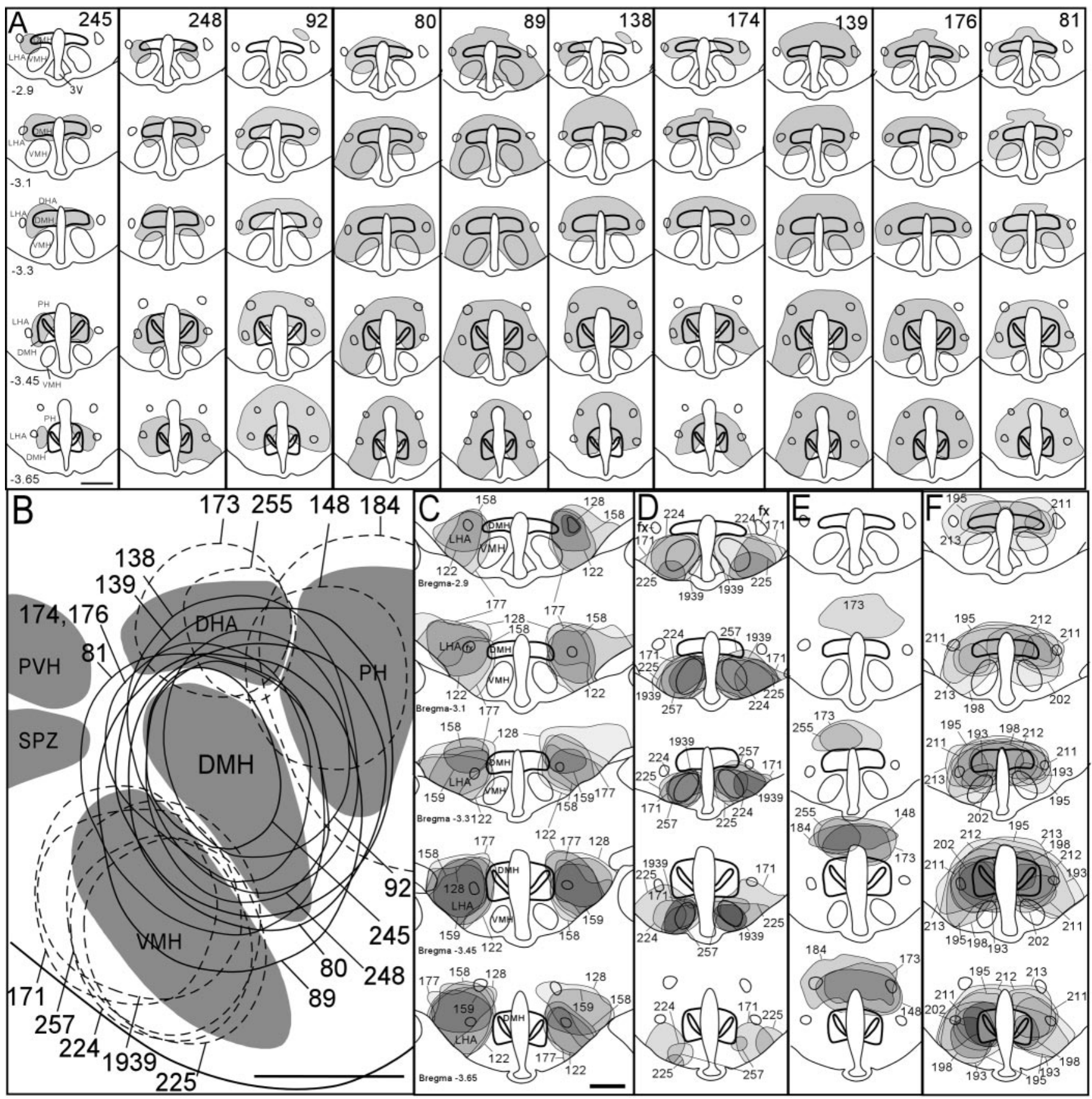

Figure 2. A, Coronal views of DMH area lesions ablating $>80 \%$ of DMH neurons. Drawings are shown in order from least (case 245 ) to greatest (case 81 ) cell loss. $B$, Reconstructions of DMH lesions (solid outlines) in a single sagittal plane $0.4 \mathrm{~mm}$ lateral to midline. Also shown are sagittal reconstructions of control lesions ventral, dorsal, or caudal to the DMH (dashed outlines). Rostral is toward the left, and dorsal is toward the top of panel. Lesions lateral to the DMH are not shown in this panel because they lie outside the plane shown. $(-E$, Coronal drawings of control lesions lateral ( $C$, ventral $(D)$, and dorsal $(E)$ to the DMH. F, Coronal drawings of DMH lesions used for melatonin/corticosteroid measurements. Scale bars, $1 \mathrm{~mm}$. Distance from bregma is indicated in millimeters for coronal sections in $A$ and $C$.

with relatively mild $(<30 \%)$ loss of PeF neurons still showed profound reductions in NREM and REM CI and cosinor amplitudes. Across all 10 DMHx rats, PeF cell loss did not correlate with reductions in the CI of REM or NREM sleep (see Fig. $3 F$ ) ( $p>0.1$ each), nor did it correlate with reductions in their cosinor amplitudes ( $p>0.1$ each).

To further control for LHA damage, we examined five rats with lesions just lateral to the DMH (Fig. 2C). These lesions ablated $87 \pm 5 \%$ of Nissl-stained neurons in the PeF but ablated only $10 \pm 6 \%$ of DMH neurons. In these rats, overall daily wake- fulness was reduced by $1.1 \mathrm{hr}$ relative to sham controls (Table 1 ) $(p<0.05)$, but behaviors were otherwise strikingly different from that of DMHx rats. LHA-lesioned rats had no reductions in the CI or cosinor amplitude of sleep, LMA, or $\mathrm{Tb}$ relative to sham-operated control rats (Table 1; see Fig. $4 H$ ), although they showed a moderate reduction in the REM rhythm that did not reach statistical significance $(38 \pm 22 \%$ CI reduction; $25 \pm 21 \%$ cosinor reduction; $p>0.1$ each comparison). LHA lesions reduced overall daily LMA by $44 \pm 4.8 \%(p<0.05)$, but these rats still had $68 \%$ more daily LMA counts than DMHx rats $(p<$ 
A

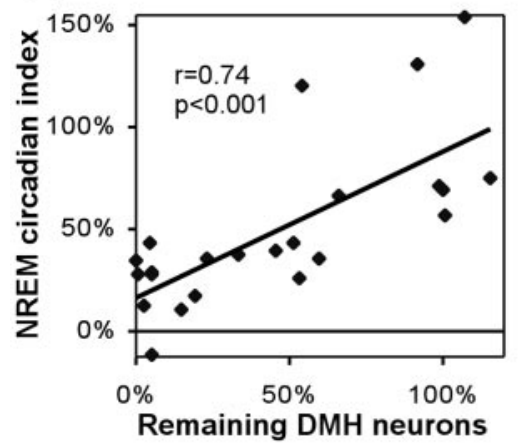

D

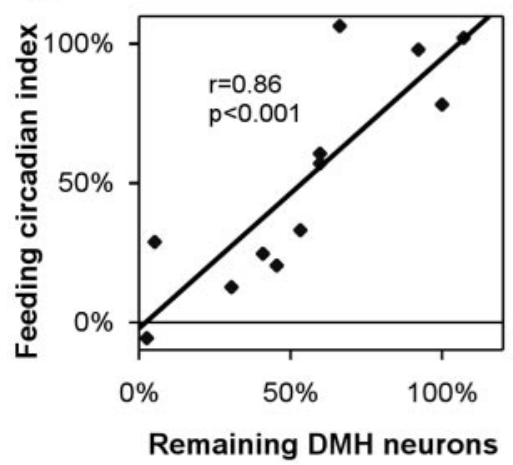

B

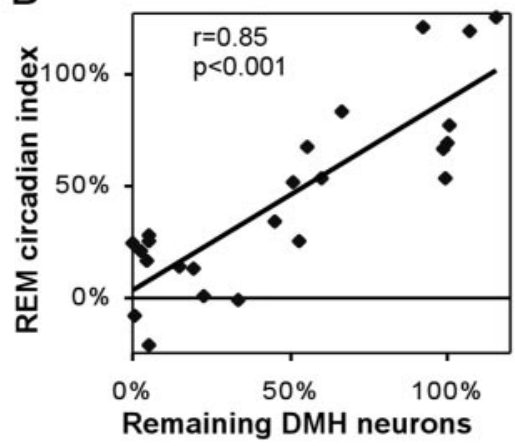

E

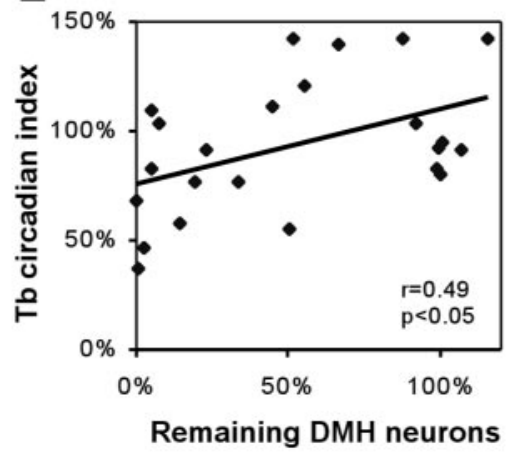

C

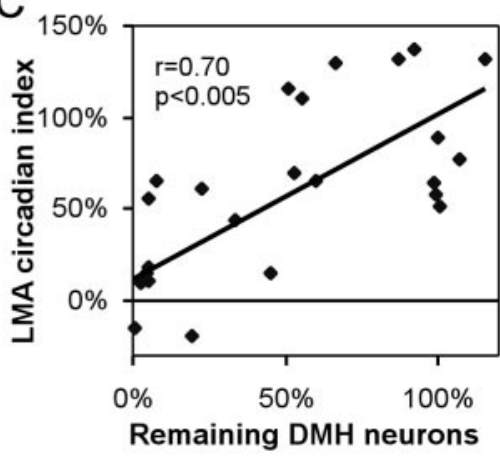

$\mathrm{F}$

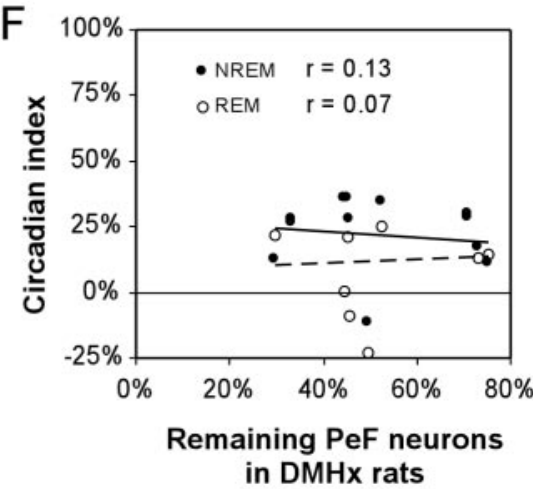

Figure 3. After DMH lesions, numbers of surviving DMH neurons correlate significantly with circadian indices of NREM sleep $(A)$, REM sleep $(B)$, LMA $(C)$, and food intake $(D)$, but not Tb $(E)$. The trend lines for sleep, LMA, and feeding, but not Tb, intersect the $y$-axis near zero, suggesting a greater DMH influence on sleep, LMA, and feeding than Tb rhythms. In DMHx rats ( $>80 \%$ loss of DMH neurons), additional loss of perifornical neurons does not correlate with additional reductions in REM or NREM circadian indices ( $F$ ). Circadian indices and cell counts are normalized to $100 \%$ for sham-operated controls.

0.01 ). LHA lesions did not reduce overall daily $\mathrm{Tb}$ (Table 1$)(p>$ $0.05)$.

It should be noted that our LHA lesions were placed as controls for damage induced by $\mathrm{DMH}$ area lesions and thus spared substantial portions of the LHA, particularly at levels rostral or caudal to the $\mathrm{DMH}$, and in the lateral-most portions of the LHA. Thus, these lesions spared $\sim 33 \pm 7 \%$ of orexin neurons throughout the entire LHA and did not produce the intense hypersomnolence seen after more extensive lesions of the LHA (Gerashchenko et al., 2001).

Lesions of the VMH $(n=5)$ (Fig. $2 D)$ or dorsal and posterior hypothalamic areas (DHA/PH) $(n=4)$ (Fig. $2 E)$ had no significant effects on the circadian indices, cosinor amplitudes, or overall levels of NREM sleep, REM sleep, LMA, or Tb (Table 1), with the exception of a $40 \pm 11 \%$ increase in the REM circadian index after VMH lesions (Table 1) $(p<0.05)$ (see Fig. $4 H$ ). The current study did not examine lesions in the dorsal SPZ, which resides just rostral to the $\mathrm{DMH}$, because cell loss in this region has been shown previously to reduce only the Tb but not sleep and LMA circadian rhythms (Lu et al., 2001).

\section{Effects on food intake}

Previous studies showed that DMH lesions modestly reduce food intake (Bernardis and Bellinger, 1998), but we hypothesized that these lesions may have greater effects on the circadian variation of feeding. In $10 \mathrm{DMH}$-lesioned and 3 sham-injected control rats (a subset of the animals used for sleep recordings), the circadian index of food intake correlated strongly with the number of surviving DMH neurons $(r=0.86 ; p<0.01)$ (Fig. $3 D)$. The animals with the three most complete lesions lost $84 \pm 11 \%$ of $\mathrm{DMH}$ neurons and had a $79 \pm 11 \%$ reduction in the circadian index of feeding relative to three sham-operated controls $(p<0.05)$. The three animals also showed a reduction in total food intake from $25 \pm 1$ to $20 \pm 4 \mathrm{gm} / \mathrm{d}$, which did not reach statistical significance $(p>0.1)$. In contrast, LHA-lesioned rats had no change in the circadian index of feeding $(p>0.50)$ but showed a $39 \%$ reduction in total feeding relative to sham-operated rats $(p<0.05)$. Hence, LHA lesions mainly disrupted homeostatic but not the circadian distribution of feeding; conversely, DMH lesions mainly affected the circadian distribution of feeding. Cell-specific $\mathrm{VMH}$ lesions did not significantly alter total food intake $(p>$ $0.1)$ or its circadian index $(p>0.2)$.

\section{DMH lesions eliminate circadian rhythm of adrenal} corticosteroids but not melatonin

The DMH has been implicated in circadian regulation of melatonin and corticosterone (Bellinger et al., 1976; Kalsbeek et al., 1996), but these previous studies used electrolytic lesions, which destroy fibers of passage, or drug injections, which may spread outside the DMH. In a separate group of DMH-lesioned $(n=6)$ and sham-operated control animals $(n=5)$, rats with DMH area lesions had no circadian variation of serum cortisol (Fig. 4I) (ANOVA; $F=0.41 ; p>0.7$ ), in contrast to sham-operated rats, which had much higher cortisol levels at 4 P.M., near the end of the subjective day, than at the other three sample times $(p<$ 0.05) (Fig. 4I). DMH lesions also reduced average daily cortisol levels nearly twofold, from $19 \pm 2$ to $10 \pm 2 \mathrm{ng} / \mathrm{ml}(p<0.01)$. Although two lesioned rats in this group (Fig. $2 F$, cases 193, 195) 

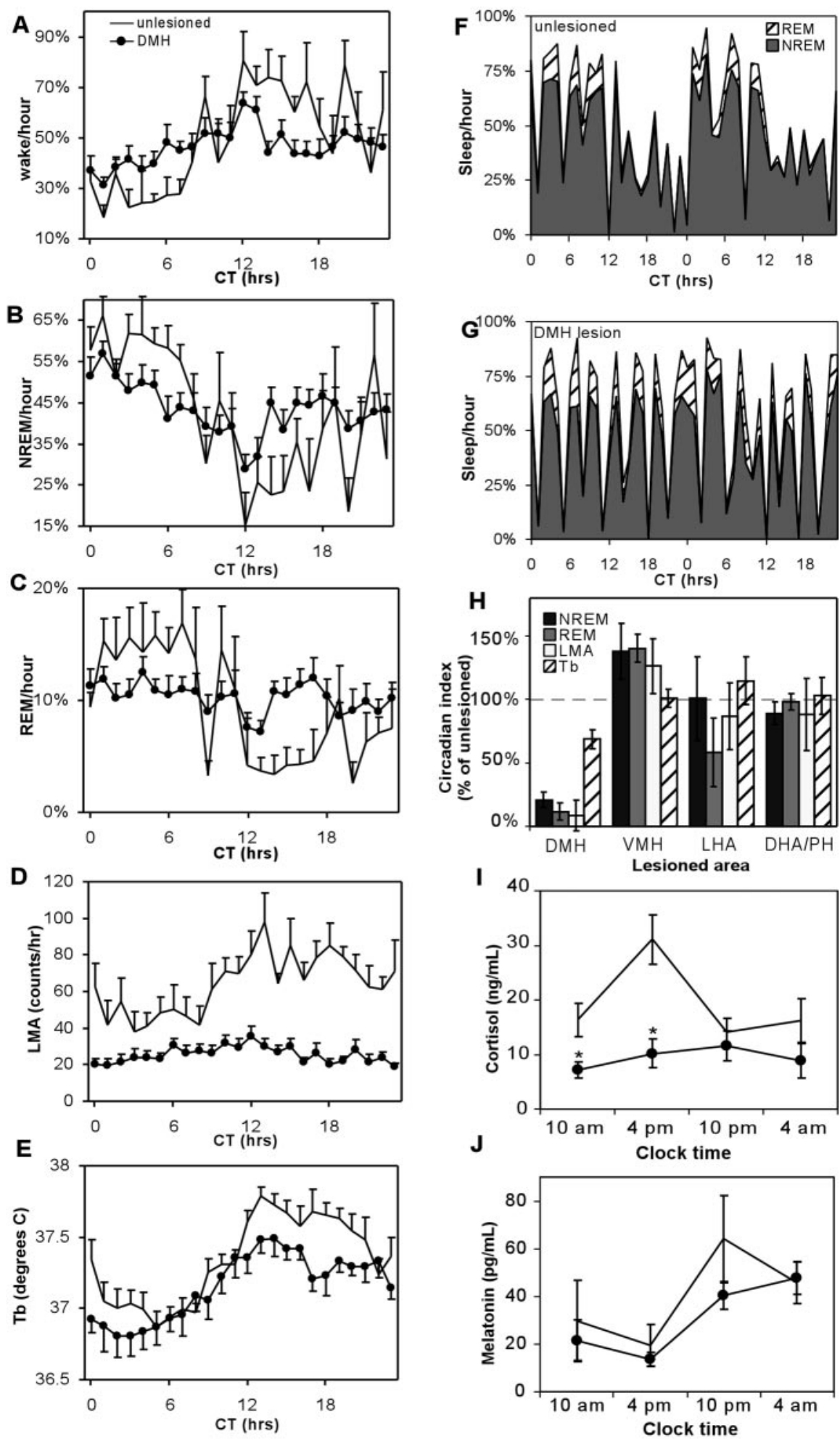

Figure 4. Hour-by-hour group averages of wakefulness $(A)$, NREM sleep $(B)$, REM sleep $(C)$, and LMA $(D)$ show marked reduction of rhythms in DMHx rats $(O)$, relative to sham-operated controls (no symbol). Results are plotted with respect to circadian time, with the subjective day onset designated CTO. Unlike other rhythms, the Tb circadian rhythm amplitude does not show a marked attenuation $(E)$. Forty-eight consecutive hours of sleep data from a single typical sham-operated control rat show robust NREM and REM circadian rhythms ( F), whereas a typical DMH lesioned rat (case 248) shows predominant 3-4hr ultradian rhythms instead (G).H, Lesions of the VMH, LHA, or DHA/PH show no change, or a modest increase, in circadian indices of sleep, Tb, and LMA, contrasting sharply with DMH-lesioned rats, which have marked reductions of sleep and LMA circadian indices (controls are normalized to 100\%). I, DMH area lesions abolish the circadian rhythm of serum cortisol and lower its overall levels but do not affect serum melatonin levels $(J)$. Asterisks in / and $J$ indicate significant differences from sham controls: ${ }^{*} p<0.05 ;{ }^{* *} p<0.01$. had damage extending laterally beyond the fornix, other DMH lesions did not extend past the fornix, yet they showed similar alterations in cortisol values. Cortisol and corticosterone levels can rise rapidly during stress, e.g., because of handling, but the serum cortisol levels of our rats were comparable with those obtained by rapid decapitation (Antonio Martinez et al., 1990).

Although corticosterone, rather than cortisol, is the predominant adrenal corticosteroid in rats, technical difficulties prevented us from obtaining sufficient corticosterone measurements for statistical analysis. We observed roughly parallel changes in these two hormones, however, consistent with their overlapping biosynthetic pathways (Fauci et al., 1998) and with other studies showing parallel changes in release of corticosterone and cortisol (Illera et al., 1998; Szucs et al., 2001). Melatonin levels were unaffected relative to saline-injected controls at all sample times (Fig. $4 J)(p>0.2$ each comparison).

\section{Circadian inputs to the DMH}

The effects of DMH lesions on sleep, LMA, and $\mathrm{Tb}$ closely resemble those of ventral SPZ lesions, which also attenuate sleep and LMA circadian rhythms to a much greater degree than $\mathrm{Tb}$ rhythms (Lu et al., 2001). We used anterograde and retrograde tracing to examine whether this functional similarity may be mediated by a projection from the ventral SPZ to the DMH. After injections of the retrograde tracer CTB into the DMH of three rats (Fig. 5A), labeled neurons were more than twice as numerous in the ventral SPZ (52 \pm 12 cells per $40 \mu \mathrm{m}$ section) as in the SCN (19 \pm 2 cells per section) or dorsal SPZ (21 \pm 2 cells per section) (Fig. 5B). Anterograde tracer injections into the ventral SPZ (Fig. 5C) confirmed this pathway, showing many labeled fibers and boutons in the DMH (Fig. 5D), particularly in rostral portions of the DMH. Some anterogradely labeled boutons apposed neurons immunoreactive for TRH (data not shown), a marker for many $\mathrm{DMH}$ neurons (Fig. $1 B, E$ ), but most boutons in the DMH intermingled with TRH somata without forming apparent appositions. Labeled fibers arising from the ventral SPZ were also apparent just outside the DMH, in the VMH, LHA, and DHA.

\section{DMH projections to sleep-wake} regulatory neurons

We previously found a strong $\mathrm{DMH}$ projection to galaninergic VLPO neurons 


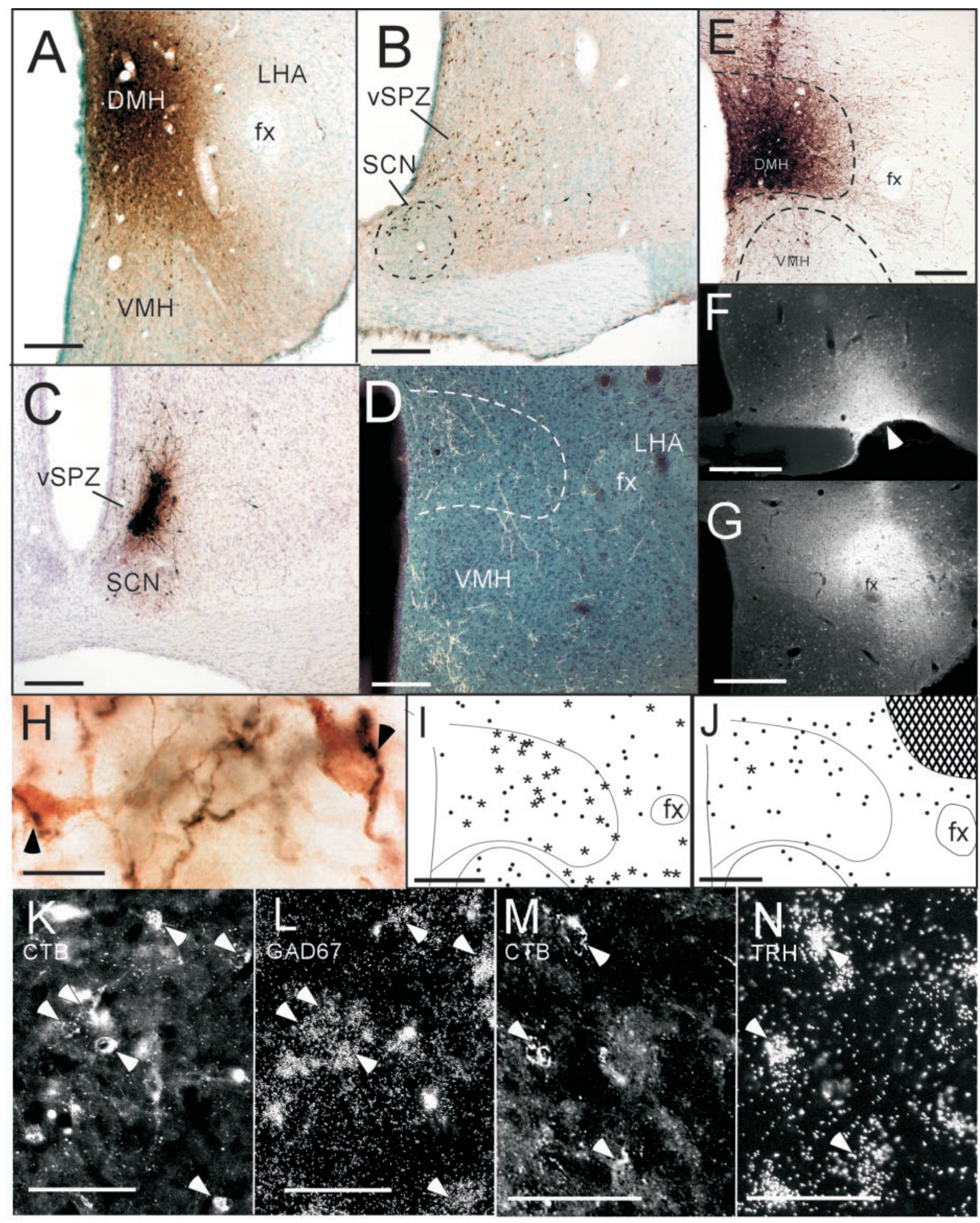

Figure 5. After retrograde tracer injections into the $\operatorname{DMH}(A)$, numerous retrogradely labeled cells are seen in the ventral SPZ, with somewhat fewer cells in the dorsomedial $S C N(B)$. Anterograde tracer injections into the ventral SPZ ( $C$ produce labeled terminals mainly in the DMH and VMH (D). After injections of the anterograde tracer biotinylated dextran into the DMH ( $E$ ), labeled fibers heavily innervate the LHA, particularly near the fornix, where many anterogradely labeled fibers $(H$, dark reaction product) appose orexin neurons (H, lighter reaction product). After CTB injections into the VLPO ( $F$, arrowhead), many DMH neurons are retrogradely labeled $(I)$, and most of these express GAD67 mRNA (asterisks), although some do not (dots). Higher magnification of DMH region shows retrogradely labeled cells (J, epifluorescence illumination) overlaid with silver grains indicating GAD67 mRNA ( $K$, dark-field illumination). Arrowheads indicate double-labeled cells. After CTB injections into the LHA ( $G$ ), very few (TB-labeled DMH neurons express GAD67 mRNA (single star), and most lack detectable GAD67 mRNA (dots). Hatched area in $J$ shows (TB injection site. Some DMH neurons retrogradely labeled by LHA injections ( $M$ ) had overlying silver grains indicating TRH mRNA ( $(N)$. fx, Fornix. Scale bars: A, D, E, G-I, L, $250 \mu \mathrm{m} ; B, C, 125 \mu \mathrm{m} ; F, 20 \mu \mathrm{m} ; J, K, 150 \mu \mathrm{m}$; $M, N, 100 \mu \mathrm{m}$. 
(Chou et al., 2002), which promote sleep. Because the DMH also heavily innervates the LHA (Thompson et al., 1996), where many wake-promoting orexin neurons are found, we examined whether DMH efferents target orexin neurons by injecting the anterograde tracer $\mathrm{BD}$ into the $\mathrm{DMH}$ of three rats (Fig. $5 E$ ). Averaged over these three cases, anterogradely labeled fibers and boutons apposed $67 \pm 13 \%$ of orexin-immunoreactive cell bodies medial to the fornix and $23 \pm 8 \%$ of orexin-immunoreactive cell bodies lateral to the fornix (Fig. $5 F$ ). Many anterogradely labeled boutons in the LHA did not appose orexinimmunoreactive somata or proximal dendrites; these boutons may target non-orexinergic neurons or unlabeled distal dendrites of orexin neurons.

Because VLPO and LHA neurons are thought to have opposing effects on sleep-wake behaviors, we hypothesized that the $\mathrm{DMH}$ projections to these areas may express opposing inhibitory and excitatory neurotransmitters. To examine neurotransmitters in DMH neurons projecting to the VLPO, we placed CTB injections into the VLPO (Fig. 5G). The injection sites in these cases included the VLPO cluster, where the densest collection of galaninergic sleep-active neurons is found (Gaus et al., 2002), and the extended VLPO, which resides dorsal and medial to the VLPO core and contains a more diffuse collection of galaninergic, sleepactive neurons. Our previous studies showed that DMH efferents abundantly appose neurons in both the VLPO cluster and extended VLPO (Chou et al., 2002).

$\mathrm{DMH}$ neurons projecting to the VLPO were predominantly GABAergic. In three cases with CTB injections into the VLPO (Fig. $5 G$ ), an average of $54 \pm 18 \mathrm{DMH}$ neurons per section were retrogradely labeled. Of these, $67 \pm 6 \%$ also expressed mRNA for GAD67, the synthetic enzyme for GABA (Fig. 5I-K). In contrast, only $14 \pm 2 \%(n=4)$ of CTB-labeled DMH neurons expressed either glutamate immunoreactivity or mRNA for VGLUT2, a recently identified marker for many glutamatergic neurons (Takamori et al., 2001). We did not examine expression of mRNA for the type 1 vesicular glutamate transporter, because its mRNA levels are very low in DMH neurons (Ziegler et al., 2002).

$\mathrm{DMH}$ neurons projecting to the LHA predominantly expressed glutamatergic markers. In five cases with CTB injections into the LHA, $45 \pm 13 \mathrm{DMH}$ neurons per section were retrogradely labeled, and $59 \pm 5 \%$ of them expressed either glutamate immunoreactivity or VGLUT2 mRNA. In three other cases with CTB injections into the LHA, only $13 \pm 3 \%$ of retrogradely labeled DMH neurons expressed GAD67 mRNA (Fig. 5L). We did not observe glutamate immunoreactivity or VGLUT2 mRNA above background levels in brain regions containing predominantly GABAergic neurons, such as the striatum, VLPO, SCN, or reticular nucleus of the thalamus.

Our CTB injections into the VLPO typically involved the supraoptic nucleus as well, a minor target of $\mathrm{DMH}$ efferents (Thompson et al., 1996); however, CTB injections confined to the supraoptic nucleus label many fewer DMH neurons than injections involving the VLPO (Chou et al., 2002).

TRH neurons are particularly numerous in the $\mathrm{DMH}$, compared with the immediately surrounding areas (Fig. $1 B, E$ ), and TRH mRNA was found in $34 \pm 8 \%$ of DMH neurons projecting to the LHA $(n=3)$ (Fig. $5 M, N)$, but in only $8 \pm 4 \%$ of DMH neurons projecting to the VLPO $(n=3)$. Hence, TRH neurons in the $\mathrm{DMH}$, like glutamatergic neurons, may preferentially project to the LHA versus the VLPO.

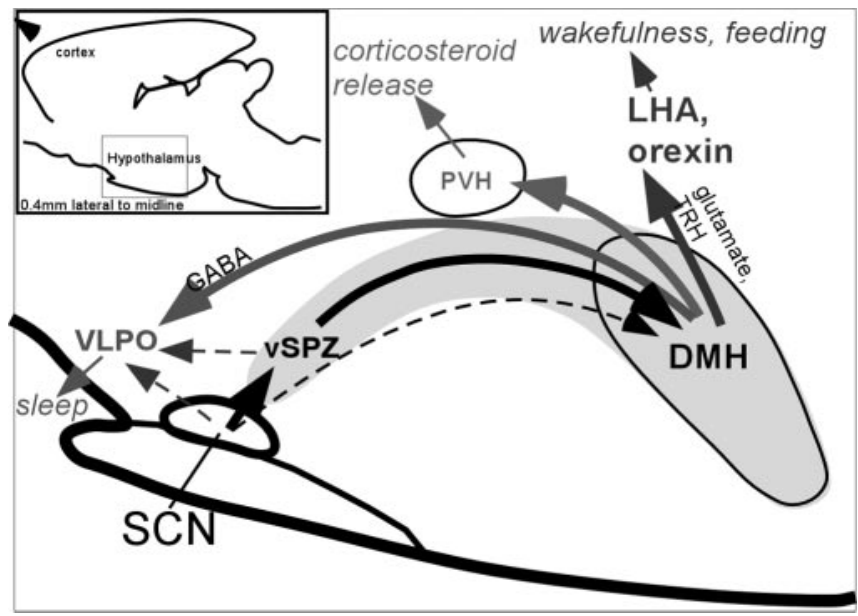

Figure 6. Sagittal view ( $0.4 \mathrm{~mm}$ from midline) of major DMH pathways regulating circadian timing of sleep, wakefulness, and hormone secretion. Solid lines indicate relatively intense pathways, whereas dotted lines indicate weaker pathways. 0ther DMH afferents and efferents not examined in this study are omitted.

\section{Discussion}

Our experiments demonstrate that the DMH plays a major role in regulating the circadian rhythm of sleep and a wide range of related behaviors. DMH lesions not only markedly reduced circadian rhythms of wakefulness, LMA, and corticosteroid secretion, but they also reduced their overall levels (as well as overall $\mathrm{Tb}$ ), suggesting that the DMH influences their circadian rhythms mainly via activation of these processes. This finding is consistent with previous studies showing that $\mathrm{DMH}$ stimulation increases heart rate, blood pressure, LMA, and Tb (Zaretskaia et al., 2002). Our anatomic findings also identify a pair of major DMH efferent pathways that could simultaneously inhibit sleep and promote wakefulness (Fig. 6). These findings provide clear evidence that the DMH plays a pervasive role in driving a wide range of behavioral circadian rhythms, including sleep-wake rhythms.

Unlike behavioral and corticosteroid rhythms, melatonin and Tb circadian rhythms do not seem to be critically dependent on the DMH. DMH lesions did not affect the circadian rhythm of serum melatonin, consistent with a previous cell-specific lesion study (Mota et al., 2001) and previous hypotheses that the SCN drives melatonin circadian rhythms via direct projections to the PVH (Klein et al., 1983; Vrang et al., 1995). DMH lesions reduced the $\mathrm{CI}$ and cosinor amplitudes of Tb by only $25-33 \%$, much less than the effects on NREM and REM sleep rhythms.

Because a minor component of the circadian rhythm of sleep remained after DMH lesions, this rhythm may also be influenced through pathways bypassing the DMH. For example, direct projections from the SCN to the VLPO could play a role, as could other brain regions, such as the ventral SPZ, that receive input from the SCN and project to the VLPO (Gaus and Saper, 1998; Gaus et al., 2000; Deurveilher et al., 2002). Other possibilities include effects on sleep of rhythms of $\mathrm{Tb}$ and melatonin and possibly other rhythms that do not critically require the $\mathrm{DMH}$.

\section{Calculations of circadian rhythm amplitudes}

We recorded sleep in constant darkness to avoid known effects of light on sleep-wake behaviors (Alfoldi et al., 1991). Because most rats' circadian periods slightly exceeded $24 \mathrm{hr}$, phase corrections were required before determining circadian indices; however, these corrections were typically minor, because most circadian periods were very close to $24 \mathrm{hr}$. Nevertheless, our results could 
be confounded if estimates of circadian period were more variable in DMHx than control rats; this would selectively degrade the circadian index in the lesioned but not control rats. $\mathrm{DMH}$ lesions did not increase the SD of estimates of circadian period, however, suggesting that phase errors were no more variable in DMHx than in unlesioned control rats. Finally, results obtained with the circadian index were corroborated with a cosinor analysis, which makes no assumptions about circadian phase. The cosinor analysis only measures sinusoidal components of a waveform, however, whereas behavioral rhythms in this study often showed abrupt changes near CT0 and CT12 that are clearly not sinusoidal. The cosinor is also systematically biased by low levels of $24 \mathrm{hr}$ components even in random noise. Both of these biases in the cosinor would reduce the apparent difference between DMHx and unlesioned rats, and indeed, cosinor reductions were typically somewhat smaller than circadian index reductions.

\section{Overall activating influence of the DMH}

In squirrel monkeys, SCN lesions reduce total wakefulness (Edgar et al., 1993), suggesting that the circadian system in this diurnal species acts mainly by increasing wakefulness during the animal's active period. SCN lesions in rats do not cause major changes in total levels of sleep and wakefulness (Mistlberger et al., 1983), however, and it has remained unclear whether the circadian system in rats promotes wakefulness at night, inhibits it during the day, or both. The current findings that DMH lesions reduce wakefulness, LMA, cortisol levels, and Tb suggest an activating role for the $\mathrm{DMH}$ in these functions. Such an activating role would also be consistent with our anatomic findings, and hence the circadian system in rats may also be mainly activating, analogous to its role in monkeys. This activation may be somewhat weaker in rats, however, because $\mathrm{DMH}$ lesions reduce total wakefulness to a much smaller extent than SCN lesions in monkeys.

\section{The DMH is a key output nucleus of the circadian system}

In agreement with our previous findings, the $\mathrm{SCN}$ appears to influence sleep and other behavioral rhythms via at least two intermediate stages: the SPZ and the DMH. We showed previously that the dorsal SPZ is critically required for $\mathrm{Tb}$ rhythms, whereas the ventral SPZ is critically required for sleep and LMA rhythms (Lu et al., 2001). The DMH may represent a major continuation of the ventral SPZ branch of circadian output, a finding that is corroborated by our observations that the $\mathrm{DMH}$ receives a larger input from the ventral than the dorsal SPZ. Unlike the SCN and SPZ, the DMH sends projections to widespread downstream targets, suggesting that the DMH is a major output nucleus of a multistage circadian outflow system.

\section{Downstream targets of the DMH}

The heaviest projections of the DMH reside within the hypothalamus, including a well studied projection to the PVH (ter Horst and Luiten, 1986; Thompson et al., 1996; Elmquist et al., 1998), a major site for regulating endocrine function including corticosteroid release (Tokunaga et al., 1986). Although the PVH does not play a major role in circadian rhythms of sleep (Lu et al., 2001), we have identified differential DMH projections to the VLPO and orexin neurons, which play major roles in promoting sleep and wakefulness, respectively. Orexin neurons may have a particularly strong influence on REM circadian rhythms, because loss of the orexin peptide or neurons nearly abolishes REM sleep circadian rhythms (Chemelli et al., 1999; Hara et al., 2001). DMH efferents also appear to target many non-orexin neurons in the
LHA. Non-orexin LHA neurons have been implicated in promoting wakefulness because large cytotoxic LHA lesions cause profound hypersomnolence (Gerashchenko et al., 2001), whereas selective loss of the orexin neurons does not (Hara et al., 2001). Some of the DMH neurons that project to the LHA express $\mathrm{TRH}$, and TRH receptors are abundantly expressed by LHA neurons (Heuer et al., 2000). It would be interesting to determine whether non-orexin neurons in the LHA promote wakefulness, express TRH receptors, and receive inputs from the DMH. Although it has been suggested that the DMH regulates sleep-wake rhythms through the LC (Jones, 1991; Aston-Jones et al., 2001), we and others have found only sparse direct $\mathrm{DMH}$ projections to the LC (Luppi et al., 1995; Thompson et al., 1996). In addition, lesions of the LC do not affect circadian rhythms of sleep under constant dark conditions (Gonzales et al., 2002), when the SCN is the chief driver of diurnal cycles. Hence, the LC probably receives its circadian timing information via an intermediate site (such as the orexin neurons in the LHA), and its activation may be a consequence of, rather than a major driver of, circadian cycles of sleep.

In addition to its projections to the VLPO and LHA, DMH efferents strongly target areas involved in anxiety, sexual behavior, and various visceromotor functions (Thompson et al., 1996; Thompson and Swanson, 2003). Additional experiments are needed to determine whether the $\mathrm{DMH}$ also modulates these functions in a circadian manner.

\section{Broader integrative role for DMH in behavioral state control}

The current findings raise the question of why so much of the SCN output signal passes through two intermediate regions before ultimately influencing sleep, LMA, corticosteroid release, and other behaviors. We hypothesize that both the ventral SPZ and $\mathrm{DMH}$ may integrate circadian timing information with other processes operating independently of circadian time. For example, the SPZ receives inputs from numerous regions, including neurons in the VMH that respond to leptin, a hormone involved in feeding and body weight regulation (Elmquist et al., 1998). The DMH also contains leptin receptors (Elmquist et al., 1998) and receives inputs from many regions of the hypothalamus, cortex, hippocampal formation, and brainstem (Thompson and Swanson, 1998). Hence, the SPZ and DMH may integrate circadian timing signals with many other signals that influence behavioral state, allowing behavior to be influenced by the circadian clock without being rigidly constrained by it. This hypothesis is consistent with many previous studies implicating the $\mathrm{DMH}$ in autonomic activation attributable to noxious, painful, or stressful stimuli unrelated to circadian time (DiMicco et al., 2002).

Our findings suggest that the DMH is a key output nucleus of the brain's circadian system, and it is required for the circadian activation of a wide range of behavioral and endocrine functions. We further hypothesize that the DMH integrates circadian timing information with various other signals that collectively influence an animal's behavioral state. Further research is needed to examine these roles of the DMH in behavioral state control.

\section{References}

Abrahamson EE, Leak RK, Moore RY (2001) The suprachiasmatic nucleus projects to posterior hypothalamic arousal systems. NeuroReport 12:435-440.

Alfoldi P, Franken P, Tobler I, Borbely AA (1991) Short light-dark cycles influence sleep stages and EEG power spectra in the rat. Behav Brain Res 43:125-131.

Amaral DG, Price JL (1983) An air pressure system for the injection of tracer substances into the brain. J Neurosci Methods 9:35-43. 
Antonio Martinez J, Vargas ML, Fuente T, Del Rio Garcia J, Milanes MV (1990) Plasma beta-endorphin and cortisol levels in morphine-tolerant rats and in naloxone-induced withdrawal. Eur J Pharmacol 182:117-123.

Aston-Jones G, Chen S, Zhu Y, Oshinsky ML (2001) A neural circuit for circadian regulation of arousal. Nat Neurosci 4:732-738.

Bellinger LL, Bernardis LL, Mendel VE (1976) Effect of ventromedial and dorsomedial hypothalamic lesions on circadian corticosterone rhythms. Neuroendocrinology 22:216-225.

Bernardis LL, Bellinger LL (1998) The dorsomedial hypothalamic nucleus revisited: 1998 update. Proc Soc Exp Biol Med 218:284-306.

Chemelli RM, Willie JT, Sinton CM, Elmquist JK, Scammell T, Lee C, Richardson JA, Williams SC, Xiong Y, Kisanuki Y, Fitch TE, Nakazato M, Hammer RE, Saper CB, Yanagisawa M (1999) Narcolepsy in orexin knockout mice: molecular genetics of sleep regulation. Cell 98:437-451.

Chen CT, Dun SL, Kwok EH, Dun NJ, Chang JK (1999) Orexin A-like immunoreactivity in the rat brain. Neurosci Lett 260:161-164.

Chou T, Bjorkum A, Lu J, Scammell T, Saper C (2002) Afferents to the ventrolateral preoptic nucleus. J Neurosci 22:977-990.

Deurveilher S, Burns J, Semba K (2002) Indirect projections from the suprachiasmatic nucleus to the ventrolateral preoptic nucleus: a dual tracttracing study in rat. Eur J Neurosci 16:1195-1213.

DiMicco JA, Samuels BC, Zaretskaia MV, Zaretsky DV (2002) The dorsomedial hypothalamus and the response to stress. Part renaissance, part revolution. Pharmacol Biochem Behav 71:469-480.

Edgar DM, Dement WC, Fuller CA (1993) Effect of SCN lesions on sleep in squirrel monkeys: evidence for opponent processes in sleep-wake regulation. J Neurosci 13:1065-1079.

Elmquist JK, Saper CB (1996) Activation of neurons projecting to the paraventricular hypothalamic nucleus by intravenous lipopolysaccharide. J Comp Neurol 374:315-331.

Elmquist JK, Ahima RS, Elias CF, Flier JS, Saper CB (1998) Leptin activates distinct projections from the dorsomedial and ventromedial hypothalamic nuclei. Proc Natl Acad Sci USA 95:741-746.

Erlander MG, Tillakaratne NJ, Feldblum S, Patel N, Tobin AJ (1991) Two genes encode distinct glutamate decarboxylases. Neuron 7:91-100.

Fauci AS, Braunwald E, Isselbacher KJ, Wilson JD, Martin JB, Kasper DL, Hauser SL, Longo DL (1998) Principles of internal medicine. New York: McGraw-Hill.

Gaus S, Chou T, Saper C (2000) Circadian control of sleep: disynaptic connections from the suprachiasmatic nucleus to the ventrolateral preoptic nucleus. Soc Neurosci Abstr 26:2024.

Gaus SE, Saper CB (1998) Efferent connections from the suprachiasmatic nucleus to the ventrolateral preoptic nucleus in the rat. Soc Neurosci Abstr 24:1920.

Gaus SE, Strecker RE, Tate BA, Parker RA, Saper CB (2002) Ventrolateral preoptic nucleus contains sleep-active, galaninergic neurons in multiple mammalian species. Neuroscience 115:285-294.

Gerashchenko D, Kohls MD, Greco M, Waleh NS, Salin-Pascual R, Kilduff TS, Lappi DA, Shiromani PJ (2001) Hypocretin-2-saporin lesions of the lateral hypothalamus produce narcoleptic-like sleep behavior in the rat. J Neurosci 21:7273-7283.

Gonzales MC, Lu W, Aston-Jones G (2002) Role of the noradrenergic locus coeruleus (LC) system in sleep and waking: circadian factors. Soc Neurosci Abstr 28:871.11.

Hara J, Beuckmann C, Nambu T, Willie J, Chemelli R, Sinton C, Sugiyama F, Yanagi K, Goto K, Yanagisawa M, Sakurai T (2001) Genetic ablation of orexin neurons in mice causes a sleep disorder similar to human narcolepsy, hypophagia, and obesity. Neuron 30:345-354.

Hepler JR, Toomim CS, McCarthy KD, Conti F, Battaglia G, Rustioni A, Petrusz P (1988) Characterization of antisera to glutamate and aspartate. J Histochem Cytochem 36:13-22.

Heuer H, Schafer MK, O’Donnell D, Walker P, Bauer K (2000) Expression of thyrotropin-releasing hormone receptor 2 (TRH-R2) in the central nervous system of rats. J Comp Neurol 428:319-336.

Illera JC, Silvan G, Blass A, Martinez MM, Illera M (1998) The effect of clenbuterol on adrenal function in rats. Analyst 123:2521-2524.

Jones BE (1991) The role of noradrenergic locus coeruleus neurons and neighboring cholinergic neurons of the pontomesencephalic tegmentum in sleep-wake states. Prog Brain Res 88:533-543.

Kalsbeek A, Teclemariam-Mesbah R, Pevet P (1993) Efferent projections of the suprachiasmatic nucleus in the golden hamster (Mesocricetus auratus). J Comp Neurol 332:293-314.
Kalsbeek A, Drijfhout WJ, Westerink BH, van Heerikhuize JJ, van der Woude TP, van der Vliet J, Buijs RM (1996) GABA receptors in the region of the dorsomedial hypothalamus of rats are implicated in the control of melatonin and corticosterone release. Neuroendocrinology 63:69-78.

Klein DC, Smoot R, Weller JL, Higa S, Markey SP, Creed GJ, Jacobowitz DM (1983) Lesions of the paraventricular nucleus area of the hypothalamus disrupt the suprachiasmatic leads to spinal cord circuit in the melatonin rhythm generating system. Brain Res Bull 10:647-652.

Lin L, Faraco J, Li R, Kadotani H, Rogers W, Lin X, Qiu X, de Jong PJ, Nishino S, Mignot E (1999) The sleep disorder canine narcolepsy is caused by a mutation in the hypocretin (orexin) receptor 2 gene. Cell 98:365-376.

Lu J, Greco MA, Shiromani P, Saper CB (2000) Effect of lesions of the ventrolateral preoptic nucleus on NREM and REM sleep. J Neurosci 20:3830-3842.

Lu J, Zhang YH, Chou TC, Gaus SE, Elmquist JK, Shiromani P, Saper CB (2001) Contrasting effects of ibotenate lesions of the paraventricular nucleus and subparaventricular zone on sleep-wake cycle and temperature regulation. J Neurosci 21:4864-4874.

Lu J, Bjorkum AA, Xu M, Gaus SE, Shiromani PJ, Saper CB (2002) Selective activation of the extended ventrolateral preoptic nucleus during rapid eye movement sleep. J Neurosci 22:4568-4576.

Luppi PH, Aston-Jones G, Akaoka H, Chouvet G, Jouvet M (1995) Afferent projections to the rat locus coeruleus demonstrated by retrograde and anterograde tracing with cholera-toxin B subunit and Phaseolus vulgaris leucoagglutinin. Neuroscience 65:119-160.

Marcus J, Aschkenasi C, Lee C, Chemelli R, Saper C, Yanagisawa M, Elmquist J (2001) Differential expression of orexin receptors 1 and 2 in the rat brain. J Comp Neurol 435:6-25.

Mistlberger RE, Bergmann BM, Waldenar W, Rechtschaffen A (1983) Recovery sleep following sleep deprivation in intact and suprachiasmatic nuclei-lesioned rats. Sleep 6:217-233.

Mistlberger RE, Bergmann BM, Rechtschaffen A (1987) Relationships among wake episode lengths, contiguous sleep episode lengths, and electroencephalographic delta waves in rats with suprachiasmatic nuclei lesions. Sleep 10:12-24.

Morin LP, Goodless-Sanchez N, Smale L, Moore RY (1994) Projections of the suprachiasmatic nuclei, subparaventricular zone and retrochiasmatic area in the golden hamster. Neuroscience 61:391-410.

Mota SR, Canteras NS, Bartol I, Skorupa AL, Scialfa JH, Terra IM, Afeche SC, Cipolla-Neto J (2001) Lesions of the dorsomedial hypothalamic nucleus do not influence the daily profile of pineal metabolism in rats. Neuroendocrinology 73:123-128.

Paxinos G, Watson C (1997) The rat brain in stereotaxic coordinates. San Diego: Academic.

Sakurai T, Amemiya A, Ishii M, Matsuzaki I, Chemelli RM, Tanaka H, Williams SC, Richardson JA, Kozlowski GP, Wilson S, Arch JR, Buckingham RE, Haynes AC, Carr SA, Annan RS, McNulty DE, Liu WS, Terrett JA, Elshourbagy NA, Bergsma DJ, Yanagisawa M (1998) Orexins and orexin receptors: a family of hypothalamic neuropeptides and $G$ proteincoupled receptors that regulate feeding behavior. Cell 92:573-585.

Sherin JE, Shiromani PJ, McCarley RW, Saper CB (1996) Activation of ventrolateral preoptic neurons during sleep. Science 271:216-219.

Sherin JE, Elmquist JK, Torrealba F, Saper CB (1998) Innervation of histaminergic tuberomammillary neurons by GABAergic and galaninergic neurons in the ventrolateral preoptic nucleus of the rat. J Neurosci 18:4705-4721.

Steininger TL, Gong H, McGinty D, Szymusiak R (2001) Subregional organization of preoptic area/anterior hypothalamic projections to arousalrelated monoaminergic cell groups. J Comp Neurol 429:638-653.

Suzuki S, Solberg LC, Redei EE, Handa RJ (2001) Prepro-thyrotropin releasing hormone 178-199 immunoreactivity is altered in the hypothalamus of the Wistar-Kyoto strain of rat. Brain Res 913:224-233.

Swanson LW (1998) Brain maps: structure of the rat brain. Amsterdam: Elsevier.

Szucs N, Varga I, Jakab C, Patocs A, Glaz E, Toth M, Kiss R, Racz K (2001) Leptin inhibits cortisol and corticosterone secretion in pathologic human adrenocortical cells. Pituitary 4:71-77.

Szymusiak R, Alam N, Steininger TL, McGinty D (1998) Sleep-waking discharge patterns of ventrolateral preoptic/anterior hypothalamic neurons in rats. Brain Res 803:178-188.

Takamori S, Rhee JS, Rosenmund C, Jahn R (2001) Identification of 
differentiation-associated brain-specific phosphate transporter as a second vesicular glutamate transporter (VGLUT2). J Neurosci 21:RC182(1-6).

ter Horst GJ, Luiten PG (1986) The projections of the dorsomedial hypothalamic nucleus in the rat. Brain Res Bull 16:231-248.

Thompson RH, Swanson LW (1998) Organization of inputs to the dorsomedial nucleus of the hypothalamus: a reexamination with Fluorogold and PHAL in the rat. Brain Res Brain Res Rev 27:89-118.

Thompson RH, Swanson LW (2003) Structural characterization of a hypothalamic visceromotor pattern generator network. Brain Res Brain Res Rev 41:153-202.

Thompson RH, Canteras NS, Swanson LW (1996) Organization of projections from the dorsomedial nucleus of the hypothalamus: a PHA-L study in the rat. J Comp Neurol 376:143-173.

Tokunaga K, Fukushima M, Kemnitz JW, Bray GA (1986) Comparison of ventromedial and paraventricular lesions in rats that become obese. Am J Physiol 251:R1221-1227.

Vrang N, Larsen PJ, Moller M, Mikkelsen JD (1995) Topographical organization of the rat suprachiasmatic-paraventricular projection. J Comp Neurol 353:585-603.

Watts AG, Swanson LW, Sanchez-Watts G (1987) Efferent projections of the suprachiasmatic nucleus: I. Studies using anterograde transport of Phaseolus vulgaris leucoagglutinin in the rat. J Comp Neurol 258:204-229.

Zaretskaia MV, Zaretsky DV, Shekhar A, DiMicco JA (2002) Chemical stimulation of the dorsomedial hypothalamus evokes nonshivering thermogenesis in anesthetized rats. Brain Res 928:113-125.

Ziegler DR, Cullinan WE, Herman JP (2002) Distribution of vesicular glutamate transporter in rat hypothalamus. J Comp Neurol 448:217-229. 